\title{
DIREITO DOS ANIMAIS
}

\author{
Irene Patricia Nohara \\ Acadêmica da Faculdade de Direito da Universidade de São Paulo
}

\begin{abstract}
Resumo:
Os animais não chegaram a atingir, em nosso ordenamento, o patamar de sujeitos de direitos. Sua proteção, no âmbito constitucional, insere-se no direito dos homens à um meio ambiente ecologicamente equilibrado. O presente trabalho discute a situação dos animais na legislação brasileira: as normas que os tutelam, os órgãos responsáveis pela aplicação da política de proteção à fauna, e outros aspectos de interesse de todos os cidadãos, uma vez que, além da fauna ser considerada como bem público, nossos problemas ambientais desencadeiam preocupações em nível mundial.
\end{abstract}

\begin{abstract}
:
Animals didn't get to achieve, in our juridical system, the category of subject of rights. Its protection, in constitutional ambit, inserts in men's right to a balanced environment. The present work discusses animals' situation in Brazilian legislation: the norms that protect them, the responsible institutions for the application of the protection's politic to the fauna, and other aspects of all the citizen's interest once, besides the fauna to be considered as a public property, our environmental problems unchain concerns in world level.
\end{abstract}

Unitermos: fauna; flora; proteção e direito dos animais.

1. Introdução

Poderíamos falar, no contexto brasileiro, em direitos dos animais, concebendo-os como potenciais sujeitos de direitos? Onde se insere a questão da proteção do animal no âmbito constitucional? Teria o Brasil um efetivo sistema de órgãos fiscalizadores para efetivar sua legislação ambiental? Teria a prática da caça sido banida em nosso País? Quais órgãos seriam responsáveis pela fiscalização da fauna? Pode o Estado legislar sobre fauna? Existem institutos capazes de garantir uma participação de maior peso dos cidadãos na defesa dos animais? 
Esse trabalho não tem por objetivo nenhuma apologia zoófila extremada, mas tão-somente o de levar - através da análise da Constituição Federal aliada à legislações específicas e doutrinárias , o que deveria ser do conhecimento de todos os cidadãos brasileiros: nossos problemas ambientais, que estão sempre desencadeando preocupações mundiais.

A fauna silvestre, como bem público, já considerada pelo legislador como fator de bem-estar do homem na biosfera deve ser preservada, como bem cíta Paulo Affonso Leme Machado:' "a parte do valor estético de manter uma flora e uma fauna ricamente variadas, há também razões práticas para fazê-lo. Descobrese muitas vezes que certas plantas têm qualidades médicas ou outras verdadeiramente únicas. Os animais têm ainda muito para nos ensinar. Assim, o órix (em desaparecimento) pode viver indefinidamente sem beber: dai pode vir a ser de grande importância como fonte de proteinas em regiões áridas à medida que a população mundial for sendo obrigada a espalhar-se por elas. Quem sabe do que as populações futuras poderão precisar? É pura loucura desperdiçar a reserva de variações genéticas tão penosamente elaboradas em milhões e milhões de anos"

2. O animal como parte do meio ambiente

A proteção dos animais insere-se, no âmbito de nossa Constituição Federal, na parte concernente ao Meio Ambiente, do Título III Da Ordem Social, especificamente no seu art. 225: "Todos têm direito ao meio ambiente ecologicamente equilibrado, bem de uso comum do povo e essencial à sadia qualidade de vida, impondo-se ao Poder Público e à coletividade o dever de defendê-lo e preservá-lo para as presentes e futuras gerações"

Segundo comentários de José Cretella Júnior, ${ }^{2}$ a norma do art. 225 mal teria sentido se não fosse completada pelo $\S 3^{\circ}$ do mesmo, que estabelece: "as condutas ou atividades consideradas lesivas ao meio ambiente sujeitarão os infratores, pessoas fisicas ou jurídicas, a sanções penais e administrativas, independentemente da obrigação de reparar os danos causados"; porém o autor indaga onde estão as sanções e quais as penas aplicáveis.

1. Paulo Affonso Leme Machado, Direito Ambiental Brasileiro, p. 402.

2. José Cretella Júnior, Comentários à Constituição Brasileira de 1988, p. 4.518. 
Já Marco Antonio Azkoul ${ }^{3}$ considera o texto inédito por responsabilizar penalmente também a pessoa jurídica, composta de todos os seus representantes legais e observa que o Decreto-Lei n. 2.645 de 10.07.1934, Lei de Proteção dos Animais, e a Lei n. 5.197, sobre a Proteção da Fauna, passaram a ser integradores da norma constitucional nos moldes acima.

Prevê também a Constituição, no inciso I, $\S 1^{\circ}$ do mesmo art. 225, o manejo ecológico das espécies e ecossistemas. Portanto, segundo Cretella, ${ }^{4}$ compete ao Poder Público prover a transferência de seres vivos, de um meio nocivo a outro meio benéfico, bem como a dos ecossistemas (considerando por ecossistema " $O$ conjunto de seres vivos de um dado meio ambiente e dos elementos não-vivos que Ihe são vitalmente ligados").

Há no inciso VI, deste mesmo parágrafo de incumbências do Poder Público, referência à promoção de educação ambiental e conscientização pública para a preservação do meio ambiente, ou seja, entre outras coisas, alertar o cidadão para que se conscientize da participação ativa que deverá ter na preservação das florestas, da fauna, dos cursos de água...

Lembrando Joaquim Luiz de Osório, ${ }^{5}$ Azkoul admite que seria um passo para o reconhecimento do direito dos animais encerrar na coletividade elementos de "civilização e educação sentimental" 6

No entanto, é no sétimo inciso do referido artigo que a questão da proteção do animal é aludida de forma mais direta, pois tal regra incumbe ao Poder Público: "proteger a fauna e a flora, vedadas, na forma da lei, as práticas que coloquem em risco sua função ecológica, provoquem a extinção de espécies ou submetam os animais a crueldade"

3. O animal: sua tutela jurídica e a fauna silvestre como bem público

Se procurarmos no Vocabulário Jurídico ${ }^{7}$ a palavra animal, nele encontraremos a seguinte explanação: "quando em poder do homem, o animal.se

3. Marco Antonio Azkoul, Crueldade Contra os Animais, p. 68.

4. Ibid., p. 4.519.

5. Ibid., p. 63.

6. A educação "sentimental" é, nessa perspectiva, um senso de obrigação moral resultante da prescrição de padrões de comportamento. 
constitui como bem seu, e assim dele pode dispor, vendê-lo, dá-lo ou trocá-lo, desde que tenha qualidade e capacidade para alienar os bens que lhe pertençam." Essa conotação deriva do Direito Romano, que classificava os animais como res nullius, ${ }^{8}$ ou seja, coisa sem dono e passível de apropriação por parte de qualquer pessoa.

O próprio art. 593 do Código Civil prescreve que são coisas sem dono e sujeitas à apropriação: "I - os animais bravios enquanto entregues à sua natural liberdade; II - os mansos e domesticados que não forem assinalados, se tiverem perdido o hábito de voltar ao lugar onde costumam recolher-se", salvo se o dono o procurar. Porém o inciso I deste artigo foi revogado pela Lei n. 5.197 de 03.01.1967 que tem, no seu art. $1^{\circ}$, a seguinte redação: "Os animais de quaisquer espécies, em qualquer fase do seu desenvolvimento e que vivem naturalmente fora do cativeiro, constituindo a fauna silvestre, bem como seus ninhos, abrigos e criadouros naturais são propriedades do Estado, sendo proibida a sua utilização, perseguição, destruição caça ou apanha."

Ou seja, os animais bravios ou silvestres foram transformados em propriedade do Estado, segundo Paulo Affonso Leme Machado, ${ }^{9}$ para bem de uso comum do povo. Não são considerados um bem patrimonial por sua utilidade pública e para a proteção do equilíbrio ecológico (a Lei n. 5.197 não se restringe à tutela dos animais, mas engloba também o seu habitat).

Assim os animais encontram-se tutelados, ao menos os que vivem naturalmente fora do cativeiro, basicamente pelas Leis n. 5.197 , de 03.01 .67 e $n$. 7.653, de 12.02.88; especificamente a fauna marinha, animais que tenham a água "como o seu normal ou mais freqüente meio de vida" encontra-se disciplinada no Decreto-Lei n. 221, de 28.02.67, conhecido como Código de Pesca, que dispõe sobre proteção e estímulos à pesca. No que concerne aos domésticos, também enquadrados no art. $5^{\circ}$ da Lei n. 5.197, segundo Ann Helen Wainer, ${ }^{10}$ são protegidos pelo ainda atual Decreto n. 24.645, de 10.07.34.

7. De Plácido e Silva, Vocabulário Jurídico, p. 153.

8. Thomas Marky, Curso Elementar de Direito Romano, p. 79.

9. Ibid., p. 402.

10. Ann Helen Wainer, Legislação Ambiental Brasileira, p. 85. 
4. A Lei n. 5.179, de 03.01.67

A Lei n. 5.179, de 03.01.67, dispõe sobre a proteção à fauna e cria seu Conselho Nacional de Proteção, ampliando a antiga conceituação de fauna, conforme o Decreto n. 24.645, de 10.07.34, para estender a proteção da norma aos ninhos, abrigos e criadouros naturais de animais fora do cativeiro.

Atribui ao Poder Público competência para criar Reservas Biológicas Naturais, estaduais ou municipais, onde são proibidas as atividades de utilização, perseguição, caça, apanha ou introdução de espécies da fauna, bem como modificação de seu meio ambiente.

A Lei n. 7.653, de 12.02.88, ampliou as penas a serem aplicadas de modo a reprimir os crimes contra animais; porém Ann Helen Wainer afirma que de nada adianta uma reforma isolada na legislação," "é preciso que haja uma ação enérgica dos órgãos fiscalizadores de modo a prevenir crimes contra a natureza, $e$, quando não possam ser prevenidos, que sejam instaurados inquéritos e levantados a julgamento dos infratores"

\section{A diferença entre o animal e o homem}

Luc Ferry, em seu livro A Nova Ordem Ecológica: a árvore, o animal $e$ o homem, indaga se a diferenciação do animal em relação ao homem teria legitimidade para tirar daquele os seus direitos.

Segundo o autor, Descartes, com o seu humanismo acentuado, distinguiu tanto e tão-bem os homens dos animais que considerou estes simples máquinas. Já Rousseau, em seu Discurso Sobre a Desigualdade dos Homens, referiu-se à aptidão dos homens para elaborar um universo que rompe com a dimensão natural da vida social ou biológica, porém frisando que, apesar da qualidade de agente livre, o homem se prejudicaria se afastasse muito da regra que lhe é prescrita.

Para Ferry admitir que o valor de uma criatura é função de sua complexidade biológica é o mesmo que se desejar uma concepção graduada de direito. Apesar de as dificuldades de Rousseau em distinguir o "selvagem" do 
animal, a exigência ética mais fundamental dos modernos, o altruísmo, é "antinatural" em seu próprio princípio, pois requer uma forma de interesse.

Ou seja, se não fôssemos tão diferentes dos animais, na perspectiva ética, nem ao menos sentiríamos piedade frente ao seu extermínio, e dessa diferença se caracteriza nossa "antinatureza."

Para a filosofia crítica, como para o judaísmo, o homem é o ser da antinatureza, e como tal o "ser-para-a-lei" deve prescrever leis e padrões de comportamento, primeiramente, porque temos a liberdade de quebrá-los e, em segundo plano, porque isso impregnará nosso senso de obrigação moral.

Afirma o autor que é inegável que o animal desperte no homem tanto os sentimentos de sadismo quanto a compaixão e, como não existe a possibilidade de sadismo em objetos inanimados, o animal, como ser "animado" que é, possuiria um interesse legítimo em que paremos de torturá-los.

Porém, pode-se constatar que apesar da luta constante em favor da consolidação dos direitos dos animais e o reconhecimento destes como sujeitos de direito, ou mesmo, da promulgação da "Declaração Universal dos Direitos dos Animais". divulgada em 1978, a efetivação das normas que visam proteger os animais deu-se mais em função da percepção da possibilidade de um desequilíbrio ambiental em escala mundial do que propriamente da constatação de que os animáis possuem direitos intrínsecos porque guardam semelhanças conosco.

\section{As três ecologias segundo Ferry}

Luc Ferry identifica três formas diversas assumidas pelos teóricos ecológicos para defender a natureza: a primeira, parte de uma visão antropocentrista, em que o homem prejudicará a sua própria existência se continuar devastando o meio ambiente portanto, não considera o animal como um ente de valor absoluto em si. A segunda, parte do princípio utilitarista de que todos os seres suscetíveis de prazer e dor devem ser considerados sujeitos de direitos e tratados como tal (opinião que se faz presente no mundo anglo-saxão). Os animais são, então, tratados em pé de igualdade com os homens. A terceira, investe o ecossistema de um valor intrínseco superior ao da espécie humana, defendendo um "contrato natural" no seio do universo no qual este tornar-se-ia sujeito de direitos. 
Os comentários de Cretella Júnior ${ }^{12}$ à Constituição Federal, de 1988, refletem claramente uma construção teórica de justificativa à defesa do meio ambiente de tendência antropocentrista: a ação humana vai aos poucos "afetando $o$ equilíbrio do meio circunvizinho e, nas últimas décadas, em razão do avanço tecnológico e do aumento extraordinário da população mundial, constituiu-se uma ameaça flagrante ao próprio destino da humanidade que, sem a menor dívida, se extinguirá, a não ser que os governantes e toda comunidade internacional, em conjunto, detenham a ação predatória do homem, que se faz sentir por motivos imediatistas traduzidos em omissões e atos positivos, destruidores da vida terrestre, marinha, atmosférica e estratosférica"

7. Competência para legislar sobre fauna

Segundo o art. 24 da Constituição Federal, em seu inciso VI, legislar sobre fauna é competência concorrente da União e dos Estados. A União não reservou para si o monopólio da legislação sobre a fauna, somente sobre a caça. Os Estados e Municípios poderão prever disposições legais subsidiariamente ao que concerne à proteção da fauna.

Paulo Affonso Lemme Machado ${ }^{13}$ relata que a Constituição de 1891 não previa competência para legislar sobre fauna ou caça; a de 1934 no seu art. $5^{\circ}$ dava competência privativa à União legislar sobre caça; porém, seu $\S 3^{\circ}$ afirmava que as leis estaduais poderiam, atendendo às peculiaridades locais, suprir as lacunas ou deficiências da legislação federal; a de 1937, no seu art. 16 (item XIV) assegurava a competência privativa da União para legislar sobre caça, mas seu art. 18 permitia que os Estados legislassem para suprir eventuais deficiências da lei federal, ou atender a peculiaridades locais, desde que não ignorassem as exigências da lei federal, ou, em não-havendo lei federal, até que essa regulasse sobre caça; na de 1946 a União legislava sobre caça, não sendo excluída a competência estadual supletiva ou complementar para essa matéria.

Somente a Constituição de 1967 mudou o sistema da caça; em seu art. $8^{\circ}$, XVII, L, $\S 2^{\circ}$ estabelecia legislar sobre caça como competência exclusiva da União, e a própria Lei n. 5.197 foi elaborada sob a égide da Constituição de 1946.

12. Ibid., p. 4.516 .

13. Ibid., p. 400 


\section{A caça}

A caça profissional, aquela que tem fins econômicos, é proibida: o Código de Caça de 43 a permitia, porém atualmente só é permitida a caça amadora preenchidos certos requisitos legais, e, segundo o art. $6^{\circ}$ da Lei n. 7.653, de 1988, embora origine diminuição das espécimes de nossa fauna, a prática fica controlada pelo Poder Público.

Segundo José Afonso da Silva, ${ }^{14}$ a lei deixa possibilidade de caça esportiva em terras de domínio privado, o que contraria a regra de que a fauna é propriedade do Estado, também autoriza e até estimula formação e funcionamento de clubes e sociedades amadoristas, de caça e tiro ao vôo (objetivando espírito associativista para a prática desse esporte), assim como construção de criadouros destinados à criação de animais silvestres para fins econômicos e industriais.

9. Política de proteção à fauna no país e alguns institutos de tutela da fauna e preservação contra a crueldade dos animais

A política de proteção à fauna do País ainda não está completamente definida, há algumas regras da Lei n. 5.197, de 67, cujo art. 36 instituiu o CNPF Conselho Nacional de Proteção à Fauna, órgão consultivo e normativo de política de proteção à fauna do País, organizado pelo Decreto n. 97.633 de 10.09.1989, integrado no Ibama, Instituto Brasileiro do Meio Ambiente e Recursos Renováveis, com finalidade de estudar e propor diretrizes gerais para:

I - Criação e implantação de Reservas e áreas Protegidas, Parques e Reservas de Caça e áreas de lazer;

II - - O manejo adequado da fauna;

III - Temas de seu interesse peculiar que Ihe sejam submetidos pelo presidente do Ibama. ${ }^{15}$

14. José Afonso da Silva, Direito Ambiental Constitucional, p. 132.

15. Regulando a política nacional do meio ambiente o Ibama (e sua atuação) está regulamentado pela Lei n. 7.735, de 22 de fevereiro de 1989, cujo art. $2^{\circ}$ dispõe: "é criado o Instituto Brasileiro do Meio Ambiente e dos Recursos Naturais Renováveis, entidade autárquica de regime especial, dotada de personalidade juridica de direito público, autonomia adninistrativa e financeira, vinculada ao Ministério do Interior com a finalidade de formular, coordenar, executar e fazer executar a politica nacional do meio ambiente e da preservação, conservação e uso racional, fiscalização, controle e fomento dos recursos naturais renováveis" Já o Decreto n. 97.946, de 11 de julho de 1989 dispõe 
Marco Antonio Azkoul ${ }^{16}$ indica de uma forma mais pragmática alguns institutos que podem ser destinados à proteção "sistemática do meio ambiente e as suas criaturas, bem como a eficaz tutela da fauna e prevenção de todas e quaisquer formas de crueldade contra os animais" são eles: o mandato de segurança, o mandato de injunção, a ação popular, os juizados especiais e também o processo legislativo popular (o referendum e o plebiscitum), não-obstante a previsão desses mecanismos, de modo a aumentar a participação direta do cidadão no Estado Democrático de Direito, nem todos se caracterizam por estar cumprindo efetivamente a finalidade pela qual foram criados.

\section{Conclusão}

Estamos ainda longe de elaborar um sistema no qual o animal é considerado com um valor intrínseco, respeitando sua individualidade, vida e lhe atribuindo direitos em pé de igualdade com os homens, como desejavam os utilitaristas ou mesmo defende Luc Ferry; porém Ann Helen Wainer ${ }^{17}$ afirma que a regulamentação ambiental da legislação brasileira, em nivel constitucional, é uma das mais avançadas do mundo.

Atualmente, a questão de defesa dos animais não deveria mais ser apreciada com preconceito - há muitas pessoas que associam a preocupação com os animais aos movimentos ecológicos mais acentuados, que defendem que o ecossistema tem valor intrínseco superior ao da espécie humana. Sem negligenciar a construção teórica da "terceira forma de ecologia" e sua influência no cenário mundial; ela é de difícil aplicação no estágio de desenvolvimento que se encontra a humanidade.

Deve-se apreciar a questão da defesa dos animais como causa de desequilíbrio do sistema que também nos envolve, e não como uma forma de exclusão dos direitos dos homens.

Quando se fala em direito dos animais também está referido o direito do homem a um meio ambiente ecologicamente equilibrado, essencial à sadia

sobre a estrutura básica do lbama e dá outras providências, sendo complementado também pela Lei $n$. 6.938 de 31 de agosto de 1981 (considerando as alterações da Lei n. 7.804 de 18 de julho de 1989).

16. Ibid., p. 77.

17. Jbid., p. 109 
qualidade de vida, impondo-se, pelo art. 225 da Constituição Federal, ao Poder Público e especificamente - à coletividade o dever de defendê-lo e preservá-lo para as futuras e presentes gerações.

11. Anexo

Declaração Universal dos Direitos dos Animais

(Proclamada pela UNESCO em sessão realizada em Bruxelas em $27.01 .1978)$

Preâmbulo: Considerando que cada animal tem direitos; considerando que o desconhecimento e o desprezo destes direitos levaram e continuam a levar o homem a cometer crimes contra a natureza e contra os animais; considerando que o reconhecimento por parte da espécie humana do direito à existência das outras espécies animais, constitui o fundamento da coexistência das espécies do mundo; considerando que os genocídios são perpetrados pelo homem e que outros ainda podem ocorrer; considerando que o respeito pelos animais por parte do homem está ligado ao respeito dos homens entre si; considerando que a educação deve ensinar à infância a observar, compreender e respeitar os animais.

\section{PROCLAMA-SE}

Art. $1^{\circ}$ Todos os animais nascem iguais diante da vida e têm o mesmo direito à existência.

Art. $2^{\circ}$ a. Cada animal tem o direito ao respeito.

b. O homem, enquanto espécie animal não pode atribuir-se o direito de exterminar os outros animais ou explorá-los, violando este direito. Ele tem o dever de colocar a sua consciência a serviço dos outros animais.

c. Cada animal tem o direito à consideração, à cura e à proteção do homem.

Art. $3^{\circ}$ a. Nenhum animal deverá ser submetido a maltrato e a atos cruéis.

b. Se a morte de um animal é necessária, deverá sel instantânea, sem dor nem angústia. 
Art. $4^{\circ}$ a. Cada animal que pertence a uma espécie selvagem, tem o direito de viver livre no seu ambiente natural terrestre, aéreo ou aquático e tem o direito de reproduzir-se.

b. A privação da liberdade, ainda que para fins educativos, é contrária a este direito.

Art. $5^{\circ}$ a. Cada animal pertence à uma espécie, que vive habitualmente no ambiente do homem, tem o direito de viver e crescer segundo o ritmo e as condições de vida e de liberdade, que são próprias de sua espécie.

b. Toda modificação deste ritmo e destas condições impostas pelo homem para fins mercantis é contrária a este direito.

Art. $6^{\circ}$ a. Cada animal que o homem escolher para companheiro tem o direito a uma duração de vida, conforme a sua natural longevidade.

Art. $7^{\circ} \quad$ a. Cada animal que trabalhe tem o direito a uma razoável limitação do tempo e intensidade do trabalho, a uma alimentação adequada e ao repouso.

Art. $8^{\circ}$ a. A experimentação animal, que implica em um sofrimento físico e psíquico, é incompatível com os direitos do animal, que seja uma experiência médica, científica, comercial ou qualquer outra.

b. As técnicas substitutivas devem ser utilizadas e desenvolvidas.

Art. $9^{\circ} \quad$ No caso do animal ser criado para servir de alimentação, deve ser nutrido, alojado, transportado e morto sem que para ele resulte ansiedade ou dor.

Art. 10 a. Nenhum animal deve ser usado para divertimento do homem.

b. A exibição dos animais e os espetáculos, que utilizem animais, são incompatíveis com a dignidade do animal.

Art. 11 a. $\mathrm{O}$ ato que leva à morte de um animal sem necessidade é um biocídio, ou seja, um delito contra a vida.

Art. 12 a. Cada ato que leva à morte de um grande número de animais selvagens, é um genocídio, ou seja, um delito contra a vida.

b. O aniquilamento e a destruição do ambiente natural levam ao genocídio.

Art. 13 a. O animal morto deve ser tratado com respeito. 
b. As cenas de violência de que os animais são vítimas, devem ser proibidas no cinema e na televisão, a menos que tenham como fim mostrar um atentado ao direito dos animais.

São Paulo, janeiro de 1996.

12. Bibliografia

AZKOUL, Marco Antonio. Crueldade contra os Animais. São Paulo : Plêiade, 1995, p. 233.

CRETELLA JÚNIOR, José. Comentários à Constituição Brasileira de 1988. Rio de Janeiro : Forense Universitária, $2^{a}$ ed., v. 8, 1993.

FERRY, Luc. A Nova Ordem Ecológica: a árvore, o animal e o homem. Trad. Álvaro Cabral. São Paulo : Ensaio, 1994.

MACHADO, Paulo Affonso Leme. Direito Ambiental Brasileiro. São Paulo : RT, $3^{\text {a }}$ ed., 1991, p. 595.

MARKY, Thomas. Curso Elementar de Direito Romano. São Paulo : Saraiva, $8^{\mathrm{a}}$ ed. 1995.

SILVA, de Plácido e. Vocabulário Jurídico. Rio de Janeiro : Forense, $11^{\mathrm{a}}$ ed., 4v., 1993.

SILVA, José Afonso da. Direito Ambiental Constitucional. São 'Paulo : Malheiros, $2^{\mathrm{a}}$ ed., 1995.

WAINER, Ann Helen. Legislação Ambiental Brasileira: Subsídios para a História do Direito Ambiental. Rio de Janeiro : Forense, 1991, p. 138. 